Cinémas

Revue d'études cinématographiques

Journal of Film Studies

\title{
Présentation
}

\section{Louise Carrière}

Volume 7, numéro 3, printemps 1997

Cinéma québécois et États-Unis

URI : https://id.erudit.org/iderudit/1000946ar

DOI : https://doi.org/10.7202/1000946ar

Aller au sommaire du numéro

Éditeur(s)

Cinémas

ISSN

1181-6945 (imprimé)

1705-6500 (numérique)

Découvrir la revue

Citer ce document

Carrière, L. (1997). Présentation. Cinémas, 7(3), 7-12.

https://doi.org/10.7202/1000946ar d'utilisation que vous pouvez consulter en ligne.

https://apropos.erudit.org/fr/usagers/politique-dutilisation/ 


\section{Présentation}

\section{Louise Carrière}

Le présent numéro questionne et étudie les relations entre le cinéma québécois et les États-Unis. Il aborde plusieurs aspects majeurs de cette problématique en se penchant principalement sur les incidences culturelles, économiques et critiques de la diffusion des films québécois aux États-Unis. Quels sont les indices statistiques de l'intérêt de la critique états-unienne face aux films québécois? Quels liens y a-t-il entre réception critique et réception commerciale? Qu'apprenons-nous sur l'identité québécoise par les critiques états-uniens? Comment voient-ils notre cinématographie? En quels termes les questions de l'américanité et de l'américanisation se posent-elles? Le cinéma québécois s'américanise-t-il?

Le cinéma, au Québec, s'est historiquement confronté, depuis près de 100 ans, à la proximité des États-Unis. Cette forte présence de notre du voisin du Sud a exercé des influences sur la formation du public et de ses goûts, sur les cinéastes québécois et leurs films. Le problème de l'identification de l'appartenance des films à la culture québécoise, canadienne, "pure laine" ou "colonisée" s'est alors posé.

Le premier et plus ancien phénomène demeure sans conteste la présence du cinéma dit "américain" dans nos salles. Dès les années vingt et trente, des intervenants influents - le clergé, les élites locales, la critique cinématographique $-s$ 'inquiètent des conséquences de l'attraction cinématographique étrangère (française de France et "américaine" des États-Unis) sur l'identité québécoise. Il n'est pas encore question du cinéma québécois, pratiquement inexistant. On se demande alors laquelle de ces deux cultures cinématographiques, française ou "américaine", doit être préférée afin d'assurer la "survie de la race" canadienne-française et catholique ${ }^{\prime}$. 
En général, la francité et l'européanité du cinéma français sont perçues comme positives et la cinématographie étatsunienne, malgré ses fortes qualités, est jugée "moralement" dangereuse (protestantisme, violence, liberté sexuelle, etc.) pour les valeurs dites authentiquement québécoises (famille, religion catholique, langue française, patrie, amour de la terre). Cette tradition critique où on identifie l'emprise étrangère comme essentiellement états-unienne et négative perdure jusqu'à aujourd'hui : le cinéma des États-Unis est pernicieux et son influence contamine nos propres films.

Depuis 1960, les cinéastes québécois ont présenté, à un niveau allégorique dans le cinéma de fiction ou de façon évidente dans le cinéma documentaire, les nombreux signes de cette conscience de la présence américaine au sein de la vie québécoise. Même s'il faudra un jour pousser plus avant notre enquête, rappelons toutefois quelques éléments de la problématique. Au niveau des sujets de films, plusieurs cinéastes choisissent de renvoyer à des événements, à des situations ou à des personnages des États-Unis. Certains exposent le paysage de nos voisins comme lieu nodal de leurs films, et plusieurs personnages de fiction sont liés au rêve américain ou aux tragédies récentes de l'Amérique ${ }^{2}$.

Au-delà de ces signes recherchés et révélateurs de la polarité américaine, une question demeure lancinante pour tous les observateurs : notre cinéma en est-il un de colonisés, un de ceux qui ne font que reprendre l'esthétique, les mythes et le savoir-faire étatsuniens, ne retenant que des caricatures aliénées de l'american way of life, contribuant ainsi à appauvrir une culture nationale ${ }^{3}$ ?

Les 20 dernières années ont permis à la critique et aux cinéastes de se prononcer avec passion sur ces enjeux et d'entonner un chant unique sur l'infiltration de la culture états-unienne dans nos films. Cette pénétration culturelle est tantôt associée aux films de Gilles Carle, tantôt aux films à grands budgets, aux coproductions ou aux films dits commerciaux, et finalement au phénomène plus général de la société de consommation. Les dernières années auraient vu croître de manière négative cette influence dans nos films ${ }^{4}$.

On a donné comme exemple d'" assimiliation culturelle américanophile " celui des coproductions où l'identité québécoise se 
dilue dans la volonté d'internationalisme pour aboutir trop souvent à des produits insipides et édulcorés ${ }^{5}$. On songe aussi à la tentation bien réelle de l'exil qui a poussé bon nombre de Canadiens, de Mack Sennett à Geneviève Bujold, Daniel Pilon, Émile Genest, Pierre David, Norman Jewison, Donald Sutherland, Yves Simoneau, à quitter la partie nationale pour se réfugier dans le travail et le confort hollywoodiens. Ces réalités omniprésentes ont édulcoré les effets positifs de la présence états-unienne. Aucune analyse à notre connaissance n'a retracé, dans l'histoire du cinéma québécois, les signes bénéfiques de cette présence, encore moins a-t-on pu retracer une analyse d'ensemble de cette américanisation-américanité, tout au plus trouve-t-on sur cette question de nombreux jugements de valeur.

Pourtant, à la lumière des dernières années, un petit nombre de critiques commence à poser l'identité québécoise au cinéma non plus simplement en termes d'intégration dans une culture américaine, mais en termes de "métissage ». Il s'agit de films qui " [...] se caractérisent par des fusions et des mélanges du cinéma direct documentaire et du cinéma de fiction ; ils brassent des éléments de culture nationale et ceux d'autres cultures, puisés dans l'immigration au Québec ou à l'étranger" (La Rochelle, p. 218). Ce mélange de textures et d'hybridation, s'il est plus facilement repérable dans les docu-drames et les films-confessions, est plus difficile à cerner dans les films de fiction comme tels et dans le développement du cinéma québécois dans son ensemble.

Le présent numéro de Cinémas se donne comme objectif d'apporter des informations supplémentaires afin de permettre une réflexion plus approfondie sur le cinéma québécois en rapport avec les États-Unis, pour mieux déterminer sa place au sein d'un cinéma non pas états-unien, mais américain.

Pierre Barrette, en premier lieu, dans une perspective sémiopragmatique, à partir des concepts d'institution et de contrats, tente de cerner au plus près la spécificité du modèle représentationnel états-unien. Il cherche à répondre à certaines questions fréquemment soulevées: qu'est-ce qu'un film hollywoodien? quel spectateur y est sous-entendu? quel rôle y jouent les différentes formes génériques? comment le contexte infléchit-il la production et la réception des films? 
Richard Magnan et Bernard Bérubé dressent ensuite un portrait historique de l'évolution de la distribution des films québécois aux États-Unis. Ils font le point sur l'évolution récente des succès en salles. Notre stratégie de pénétration du marché américain a-t-elle connu principalement des succès ou des échecs?

Les critiques, plus que le public en général, ont eu accès au cinéma québécois qui est présenté souvent dans les circuits noncommerciaux. En se fiant aux répertoires critiques ${ }^{6}$, Louise Carrière étudie la réception de films québécois d'auteurs de la période 1978-1992. Elle s'intéresse plus particulièrement à une douzaine de films récents recueillant le plus grand nombre d'entrées critiques. Elle dévoile ce que la critique a dit de ces films tout en s'intéressant aussi aux présupposés et aux préjugés de la critique corporative elle-même. Pierre Véronneau, quant à lui, aborde tout un pan méconnu de l'histoire du cinéma québécois, c'est-à-dire celui des films québécois réalisés en anglais et distribués aux États-Unis. Comment évaluer leur impact? Qu’ont-ils de spécifique? Comment la critique états-unienne les perçoitelle? Quelles incidences cela occasionne-t-il sur leur succès en salle? Un corpus impressionnant de plus de 150 films permet une première saisie historique et analytique de films commerciaux distribués aux États-Unis.

Denis Bachand explore les stratégies argumentaires de trois films de Denys Arcand, Le Déclin de l'empire américain, Jésus de Montréal et Love and Human Remains pour dévoiler les filtres culturels qui régissent l'appropriation des œuvres au sein de ces communautés interprétatives. Il développe une comparaison pertinente entre ses recherches sur la réception française et ses observations sur la réception états-unienne pour en saisir les traits identitaires et les clivages qui s'installent compte tenu de la langue et de la nationalité.

Le travail d'Yves Picard ouvre directement à la problématique de l'américanisation: le cinéma québécois a-t-il renforcé récemment son emprunt aux modes de narration et de représentation états-uniens? Cela va-t-il jusqu'à influencer le cinéma de genre québécois, les téléfilms ou même le film plus intimiste des années 1980 à 1996? Michel Arsenault poursuit la réflexion sur cette problématique en s'appuyant sur les images numériques. 
L'utilisation d'images virtuelles, comme dans Screamers (Christian Duguay, 1996), nous place-t-elle à la remorque des grands mythes hollywoodiens?

Pour conclure, Joseph I. Donohoe, Jr. expose son expérience, comme enseignant aux États-Unis, de la réception des films québécois auprès de ses étudiants. Il développe un argument en faveur de la "transparence culturelle" des films destinés au marché international.

À l'époque de la mondialisation, les questions posées par ce numéro veulent donner une perspective plus large que le pessimisme de bon ton sur l'assimilation de toutes les cinématographies nationales par le cinéma des États-Unis. Les rapports de fascination qu'exercent les grandes nations sur les petites ne doivent pas nous empêcher de regarder sans complaisance les relations inégales qu'ils entretiennent, le parcours parfois sinueux de leurs interrelations et les réajustements constants que la cinématographie d'un petit pays doit opérer avec les grands ensembles culturels internationaux.

\section{Cégep du Vieux-Montréal}

\section{NOTES}

1 Voir Notre américanisation. Enquête de la revue Dominicaine (Montréal: L'Euvre de la presse dominicaine, 1937) et en particulier, l'article d'Alban Janin, "Notre américanisation par le cinéma" (p 69-97).

2 Voir le numéro de la revue Cinémas (vol. 1, $\mathrm{n}^{*} 1-2,1990$ ), portant sur l'américanité et le cinéma. Voir aussi un numéro de la revue Lumières intitulé "Vivre avec Hollywood ", n" 29 (1992) et nos articles: "Ce diable d'Amérique", Cinébulles, vol. 14, n 2, (1995); "L'Amérique, décor de cinéma", Cinébulles, vol. 14, n 3, (1995); "Assumer son américanité", Cinébulles, vol. 14, n" 4 (1996).

3 Voir le manifeste de l'Association professionnelle du cinéma québécois, Le Cinéma, un autre visage du Québec colonisé (Montréal, 1971); Fernand Dansereau, "Le cinéma québécois, un cinéma colonisé ", Cinéma Québec, vol. 3, n* 9-10 (1974), p. 80-83. Même les Français se posent récemment les mêmes questions; là-dessus voir Edward Behr: Une Amérique qui fait peur (Paris: Plon, 1995).

4 Sur la présence états-unienne dans les salles québécoises, voir Huguette Roberge, "Qui décide de ce que nous verrons au grand écran?", La Presse, 10 février 1996, p. C1-C2.

5 Voir Chantal Nadeau, "Américanité ou américanisation: l'exemple de la coproduction au Québec", Cinémas, vol. 1, n" 1-2 (1990), p. 60 à 71 .

6 Le groupe de recherche sur la réception du cinéma québécois, dirigé par Michel Larouche de l'Université de Montréal, a étudié depuis 1990 différents cas types de 
réception du cinéma québécois à l'étranger. Il a publié de nombreux documents relatifs à cette recherche dont des répertoires analytiques sur la réception du cinéma québécois en France et aux États-Unis, et sur lesquels plusieurs auteurs du présent numéro appuient leurs analyses.

\section{OUVRAGE CITÉ}

La Rochelle, Réal. "Le cinéma québécois en voie d'assimilation ou de métissage?", Les Pratiques culturelles des Québécois. Une autre image de nous-mêmes. Québec: Institut québécois de recherche sur la culture (1986), p. 215-232. 